\title{
Enrichment promotes learning in fish
}

\author{
David A. Strand ${ }^{1,3}$, Anne C. Utne-Palm ${ }^{1}$, Per J. Jakobsen ${ }^{1}$, Victoria A. Braithwaite ${ }^{1,2}$, \\ Knut H. Jensen ${ }^{1}$, Anne G. V. Salvanes ${ }^{1, *}$ \\ ${ }^{1}$ Department of Biology, University of Bergen, Bergen 5020, Norway \\ ${ }^{2}$ School of Forest Resources and Department of Biology, Penn State University, University Park, Pennsylvania 16802, USA \\ ${ }^{3}$ Present address: Section of Mycology, National Veterinary Institute Norway, Oslo 0106, Norway
}

\begin{abstract}
Captive birds and mammals reared in enriched rearing environments have been shown to behave more flexibly compared to animals reared in impoverished or plain environments. Recent evidence has shown that this is also true for fish; enrichment promotes faster recovery after a stressful experience, a higher propensity for exploration of novel areas and the development of more sophisticated social behaviour. Here we report how enrichment influences social learning in juvenile cod Gadus morhua that were reared in either spatially enriched or plain tanks. Naïve juvenile cod were allowed to repeatedly observe experienced tutors as they foraged on gammarid or mysid prey, or control tutors that acted as social stimuli but did not forage. The naïve fish then received a mixture of mysid and gammarid prey. Enriched-reared fish improved their ability to consume live prey in the presence of foraging tutors, but plain-reared fish did not. Although gammarids were consumed more often and more quickly than mysids, both among tutors and naïve fish, social learning from tutors demonstrating mysid hunting and consumption had its greatest effect on social learning in the enriched fish.
\end{abstract}

KEY WORDS: Behaviour $\cdot$ Cod $\cdot$ Gadus morhua $\cdot$ Habitat enrichment $\cdot$ Social learning $\cdot$ Feeding behaviour $\cdot$ Conservation $\cdot$ Stock enhancement

\section{INTRODUCTION}

Animals can improve their foraging ability and refine their social behaviour by learning from previous experiences (Pitcher et al. 1982, Suboski 1989, Sackett et al. 1999, Braithwaite \& Salvanes 2005, Laland \& Janik 2006). Animal development and the evolution of behaviour patterns, morphology and life-history traits are also strongly influenced by the environment (Magurran 2005). In mammals and birds, complex environments stimulate the development of neural tissue, cognitive performance and flexible behaviour (Hunter et al. 2002, Kempermann et al. 2002, Bredy et al. 2003, Rabin 2003). For example, food storing birds have a larger hippocampus than non-storing birds (Clayton \& Krebs 1994), and more diverse behaviour and better stress responses are promoted in rodents when they experience environmental complexity (Sackett et al. 1999, Harris et al. 2009). Individuals from complex environments are also more likely to approach novel stimuli (Meehan \& Mench 2002). This could promote learning opportunities that may help the animal develop problem-solving strategies, features that will be important for tackling variable natural ecosystems.

Similar effects have also been found in fish. Recent work has shown that the development of various fish behaviours are influenced by the experience of environmental complexity (Brown et al. 2003, Braithwaite 2006, Braithwaite \& Salvanes 2005). Berejikian et al. $(2000,2001)$ have reported that rainbow trout Oncorhynchus mykiss reared in enriched environments were socially dominant to size-matched fish reared in plain environments. In juvenile Atlantic cod Gadus morhua, experience with spatial structures in the nursery environment increased behavioural flexibility (Salvanes \& Braithwaite 2005, Salvanes et al. 2007). Cod reared with spatial enrichment explored a novel area 
faster, they paid more attention to live prey, and they recovered from simulated predator attacks more quickly than fish reared in plain tanks (Braithwaite \& Salvanes 2005). The social skills of enriched-reared fish (hereafter enriched fish) are also more sophisticated than in plain-reared fish (hereafter plain fish): enriched fish discriminate between fish in aggressive acts and display more often towards plain fish (Salvanes \& Braithwaite 2005). Cod with experience of spatial enrichment also vary their shoaling responses across different environments, whereas plain fish did not (Salvanes et al. 2007). Thus, enrichment in early life promotes behavioural flexibility; however, the effects of enrichment of the rearing environment on social learning ability in fish have not yet been addressed.

Social stimuli in themselves influence an animal's capacity to learn. The ability to respond to social stimuli has traditionally been considered to be more common in 'large brain' taxa. Research has now shown, however, that organisms from other taxa such as insects and fish are capable of benefitting from cues socially obtained from conspecifics (Brown \& Laland 2003, Leadbeater \& Chittka 2007). Social stimulation can directly affect foraging success by allowing observers to learn from knowledgeable demonstrators. Learning in this way reduces the costs of individual sampling (Laland \& Janik 2006). Guppies Poecilia reticulata exposed to social environments during their development have altered learning abilities; individuals reared in low-density groups were better at using social information, and were also better at locating food, than guppies reared in high-densities (Chapman et al. 2008). Social cues and public information can be used to evaluate risks such as recognising the presence of predators through expressed conspecific fright responses, to learn migration routes, to learn about mating opportunities, and to collect information about food (quality and location) (Brown \& Laland 2001, 2003, Braithwaite \& Salvanes 2008). Furthermore, socially enhanced foraging behaviour has been shown in several species of fish (Pitcher et al. 1982, Morgan \& Colgan 1987, 1988, Pitcher \& House 1987, Ryer \& Olla 1991, 1992, Laland \& Williams 1997, Brown \& Laland 2002). For example, chum salmon Oncorhynchus keta observing other fish eating were also more motivated to eat (Ryer \& Olla 1991). Reader et al. (2003) also demonstrated that wild guppies could acquire foraging skills and predator escaperesponse cues from conspecifics.

To test the hypothesis that enriched rearing environments will promote social learning ability of foraging behaviour, we reared juvenile Atlantic cod Gadus morhua in tanks with or without structural enrichment. Fish were then observed feeding on 2 different species of live prey after they had watched tutors demonstrating how to forage on different kinds of prey.

\section{MATERIALS AND METHODS}

Rearing. To minimize domestication effects, we used the F1 offspring from a brood stock of wild-caught Atlantic cod from south-western Norway that were housed at the Sagafjord Sea Farm AS, Stord, Norway. In May 2005, 8 wk old juvenile cod weighing $\sim 0.5 \mathrm{~g}$ arrived at the Department of Biology, University of Bergen.

Fish were randomly divided (with equal densities) into eight $600 \mathrm{l}$ replicate, hatchery, fibreglass tanks $(100 \times 100 \times 60 \mathrm{~cm})$ with 125 fish per tank. We used 96 juvenile Atlantic cod for the current experiment: 24 fish were used as tutors and 72 fish were tested to screen their learning. Remaining fish were subsequently used in other experiments. Of the 8 tanks, 4 were spatially enriched with rounded stones $(5$ to $20 \mathrm{~cm}$ diameter) covering $65 \%$ of the bottom and a plastic model of kelp seaweed (8 'leaves' $\sim 30$ to $40 \mathrm{~cm}$ long and 10 to $20 \mathrm{~cm}$ wide). The other 4 tanks were plain (Braithwaite \& Salvanes 2005, Salvanes \& Braithwaite 2005). In the enriched tanks, the model kelp and some of the stones were repositioned once a week (relative to the water-inlet), to simulate a changing environment. To control for handling effects, all rearing tanks received the same level of disturbance during siphoning (once a week) and cleaning (once every $6 \mathrm{wk}$ ). The tanks were supplied with aerated flow-through seawater $\left(10 \pm 1^{\circ} \mathrm{C}\right)$. We used a simulated natural photoperiod of Bergen $\left(60^{\circ} 25^{\prime} \mathrm{N}, 5^{\circ} 20^{\prime} \mathrm{E}\right)$ from May to October, including dusk and dawn. From October until the end of the experiment in December, we used a $12 \mathrm{~h}$ light: $12 \mathrm{~h}$ dark photoperiod. Fluorescent tubes (Osram L 36W/12-950, Lumilux de luxe, Daylight) were positioned $1.5 \mathrm{~m}$ above the water surface, centred over each tank. Food was delivered from a fixed position during the entire rearing period using an automated feeder. A fixed quantity of pellets, which increased in size and amount as the fish grew, were provided at intervals of 15 min daily from 08.00 to $17.00 \mathrm{~h}$.

When the fish were 25 wk old (mean total length: $13.85 \pm 0.18(\mathrm{SE}) \mathrm{cm}$, mean total weight $28.22 \pm 1.08 \mathrm{~g})$, all were PIT-tagged under metacaine $\left(0.5 \mathrm{~g} \mathrm{l}^{-1}, \mathrm{MS} 222\right)$ induced anaesthesia. Small PIT-tags (0.11 g) were inserted into the body cavity of the abdomen through a 2 to $3 \mathrm{~mm}$ incision. After recovery in a $20 \mathrm{l}$ aerated tank, the fish were released back into their respective rearing tanks. The PIT tags were small $(<0.4 \%$ of body weight) and did not have adverse effects on fish as $>99 \%$ of the fish recovered from the anaesthesia after they were tagged. The tagging allowed us to identify individual fish. At the end of the experiment the fish were killed by a blow to the head followed by exsanguination. The departmental research ethics board at the Department of Biology, University of Bergen, 
approved the experiment under the Norwegian Veterinary Authorities site licence number 18.

Live Prey. The novel prey items used for the experiment were live gammarids Gammarus locustra and mysids Praunus flexuosus. These are natural prey for wild juvenile cod, but our captive-reared experimental fish had no prior experience with these invertebrates. Prey were caught locally and kept alive in separate holding tanks and were given pellet food (Gammar pellet size 1). Gammarids were caught regularly and kept in a 151 tank with rocks to hide under. Mysids were held in a 601 tank at higher densities, as this species tend to shoal in the wild. Mean lengths (tip of rostrum to tip of telson) of gammarids were $11.5 \pm 0.5$ (SE) $\mathrm{mm}(\mathrm{n}=30)$ and mysids were $16.6 \pm 0.5 \mathrm{~mm}(\mathrm{n}=30)$, and well below maximum prey size for the fish. Hence, handling differences due to different prey size should not confound the experiment.

Tutors. Three groups of cod (mean total length of fish: $18.71 \pm 0.37 \mathrm{~cm}$ ) were trained to become tutors. Each tutor group was allocated to separate aquaria $(54 \times 38 \times 38 \mathrm{~cm})$ with flow-through seawater $(10 \pm$ $\left.1^{\circ} \mathrm{C}\right)$. Each group consisted of 8 fish selected at random, one from each of the 4 replicate rearing tanks: 4 from enriched- and 4 from plain rearing tanks. One group was trained to feed on mysids (hereafter called mysid tutors), another group was trained to feed on gammarids (hereafter called gammarid tutors) and a third group was a control for social stimuli (hereafter called control tutors; i.e. these fish were present but were not feeding when they were in visual contact with naïve fish in their acclimation day prior to trials). The control tutors were maintained on pellet food while they were housed in the separate 'tutor' aquarium, but were not fed in the presence of naïve fish. The mysid and gammarid tutors gained experience feeding on live food over a period of $2 \mathrm{wk}$, before the main experiment began. During that period the gammarid and mysid tutor groups were exposed to their live prey 22 times. At each exposure, the groups were given 16 live prey animals. After the third day of training, the mysid and gammarid tutors started to feed immediately, and most prey items were consumed within 10 min. Thus, through experience, the tutor cod learned to handle live prey efficiently. The control group was fed pellets, in an equal number compared to live prey during this $2 \mathrm{wk}$ period, at the same time as the live prey tutor groups were trained to feed.

Experiment trials. Eight test aquaria $(69 \times 34 \times$ $34 \mathrm{~cm}$ ) were used. These were divided in the middle by a clear glass wall, permitting only visual contact between tutor fish and the naïve fish. Each compartment contained $\sim 30$ l, with flow-through seawater (1 l water $\mathrm{kg}^{-1}$ fish $\mathrm{min}^{-1}$, at $10 \pm 1^{\circ} \mathrm{C}$ ) and an air-stone to keep the oxygen content in the water $>90 \%$. The 8 aquaria were visually isolated from each other so fish could only see what was going on inside their own tank. All trials were randomly distributed and conducted within a period of $32 \mathrm{~d}$, starting in November, when the fish were 32 wk old (mean total length of experimental fish: $19.21 \pm 0.21 \mathrm{~cm}$ ) measured after the test. A total of 12 replicates were conducted for naïve enriched and plain fish with 8 parallel replicates run daily.

Throughout the trials, all fish were carefully handled to minimise stress responses. The fish were given $43 \mathrm{~h}$ to acclimate to the experimental aquaria before trials began. Although previous experiments suggest that juvenile cod can recover from handling within $1.5 \mathrm{~h}$ (Artigas et al. 2005), we chose to use a prolonged acclimation period to minimise any stress that may be associated with transferring the naïve test fish from a large rearing tank into a smaller test aquaria.

Single naïve fish from each of the replicate rearing tanks were placed into test aquaria at 16:00 h. The next morning (acclimation day) at 09:30 h, 2 tutor fish were randomly chosen and put in the opposite compartment from the naïve fish and left for $90 \mathrm{~min}$. At 11.00, 12.00 and $13.00 \mathrm{~h}$ gammarid tutors received 3 gammarids, mysid tutors received 3 mysids and the control tutors and the naïve fish did not receive any prey. To examine how efficiently tutors took prey, the number of food items eaten by tutors at 5, 10, 15 and 60 min was recorded. At $15.00 \mathrm{~h}, 30 \mathrm{sec}$ after the gammarid and mysid tutors were fed, the naïve fish received 6 live prey at once: 3 mysids and 3 gammarids (Fig 1). The training procedure was staggered by 20 min for each of the 8 aquaria. After this phase was completed, tutors were transferred back to their holding aquaria using a hand net. Then the naïve fish were given pellets $(1 \mathrm{~g}$ each) to standardize the fish feeding motivation level. Leftover pellets were observed in all aquaria and removed the next morning $2 \mathrm{~h}$ before trials began.

The following day was the experimental day for the naïve fish. At $11.00 \mathrm{~h}$, they were given 6 food items (3 live mysids and 3 live gammarids). The fish were tested without tutors being present (Fig. 1). Feeding behaviour of naïve fish was filmed for 15 min using a digital video camcorder (Canon MV700i) generating detailed observations of prey pursuit and feeding successes. Numbers of prey left were counted at 30,60 and 120 min by inspecting the tank through a small viewingslit in the black curtains that surrounded each aquarium. See Fig. 1 for a schematic experimental set-up.

Behavioural analysis. Data were collected from 3 sources: (1) video recordings of naïve fish feeding behaviour, (2) direct observations of prey left in test compartments at fixed time points, and (3) direct observation of prey left in tutor fish compartments at fixed time points. Weight in grams $(W)$ and total length 


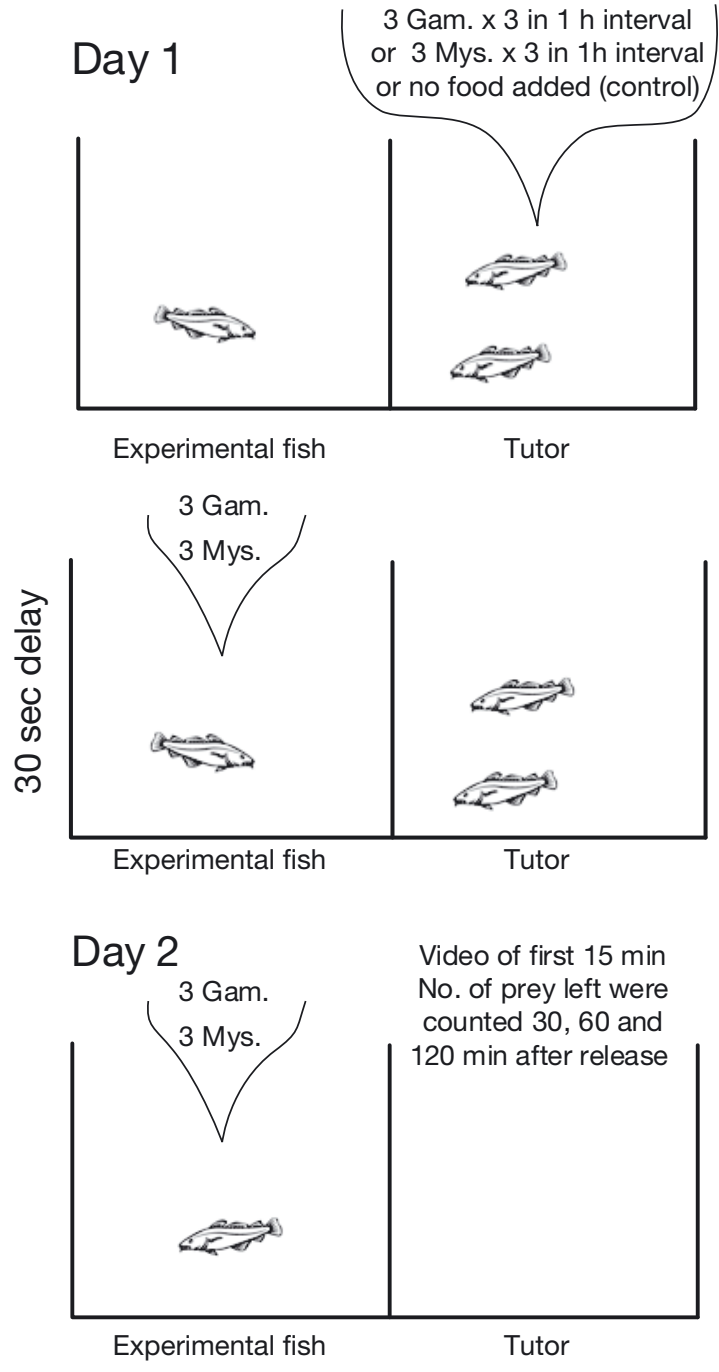

Fig. 1. Gadus morhua. Experimental set-up. Day 1: training and acclimation day for the naïve fish. Naïve fish observed their tutor fish feeding on 1 of the 2 prey types or not feeding at all (control), before receiving 6 prey ( 3 gammarids and 3 mysids) after a 30 sec delay. Day 2: experimental day, started by introducing 6 prey ( 3 gammarids and 3 mysids) to the experimental fish with no tutor present. For the first 15 min after prey introduction, feeding behaviour of naïve fish was video recorded. We further checked number and type of prey left in the experimental aquarium 30,60 and 120 min after introduction. Gam.: gammarids; mys.: mysids

in $\mathrm{cm}(L)$ of each naïve fish were measured after the second day, and Fulton's condition factor $(C F=$ $100 \mathrm{WL}^{-3}$ ) was calculated to compare the effect of rearing environment and to calculate the mean size of fish in each trial group (Table 1).

Video recordings of feeding behaviour: Naïve fish feeding behaviours were analysed using the video tapes played on a Sony digital videocassette recorder (type: DSR-20P) and a 28' LG colour screen. The recorder's timer was reset to the time live preys were introduced into the naive fish compartments. This allowed accurate timing of events when naïve fish pursued, attacked and ate live prey during the first $15 \mathrm{~min}$ of each trial. The observer was blind to the rearing background and assigned tutor group of the naïve fish. We noted (1) number of pursuits: defined as the number of times a cod chased a prey. We defined this as swimming intentionally towards a prey at any speed and when the snout of the naïve fish reached $\sim 3 \mathrm{~cm}$ or closer to the prey; (2) Number of attacks: defined as the number of times a cod opened and shut its mouth in an attempt to capture the prey, whether successful or not. (3) Prey rank: the prey eaten was given a rank number with the first item eaten given number 1 , second eaten number 2, and like this successively to number 6 , thus assessing the order in which prey were eaten ${ }_{i}(4)$ Time until prey was eaten: the time (s) from prey being introduced to the test compartment and until it was eaten; (5) Prey type: the type of prey pursued, attacked and eaten was categorized.

Direct observation of prey left for naïve fish: Through a slit in the curtains covering the aquaria, the total number of prey eaten was recorded at 15, 30, 60 and $120 \mathrm{~min}$ after the live prey were provided to the naïve fish. We also noted the time until the first prey was eaten, and if one prey was eaten since the last inspection, we also noted whether it was a gammarid or a mysid. Only on a few occasions was more than one prey removed between 2 successive inspection time points.

Direct observation of prey left by tutors: To examine how efficiently tutors pursued and ingested gammarids and mysids, we counted the number of prey left in their compartments at 5,10, 15 and 60 min and during the time period they were allowed to demonstrate prey pursuit to the naïve fish. We categorised these numbers into ranks and call them tutor rank. Rank $=1$ means that all prey were eaten within $5 \mathrm{~min}$; rank $=2$, between 5 and $10 \mathrm{~min}$; rank $=3$, between 10 and $15 \mathrm{~min}$; rank $=4$, between 15 and $60 \mathrm{~min}$; and rank $=5$ means there were prey left after $60 \mathrm{~min}$. There were no

Table 1. Gadus morhua. Mean length and weight of naïve fish used in the experiments

\begin{tabular}{|lccccc|}
\hline Rearing & $\begin{array}{c}\text { Tutor } \\
\text { feeding } \\
\text { type }\end{array}$ & $\begin{array}{c}\text { Mean } \\
\text { lenght } \\
(\mathrm{cm})\end{array}$ & SE & $\begin{array}{c}\text { Mean } \\
\text { weight } \\
(\mathrm{g})\end{array}$ & SE \\
\hline Enriched & Control & 19.34 & 0.52 & 74.18 & 5.70 \\
Enriched & Gammarids & 19.16 & 0.52 & 70.37 & 6.71 \\
Enriched & Mysids & 19.52 & 0.70 & 79.50 & 9.97 \\
Plain & Control & 19.25 & 0.47 & 70.79 & 5.91 \\
Plain & Gammarids & 18.81 & 0.56 & 67.79 & 6.60 \\
Plain & Mysids & 19.21 & 0.40 & 70.56 & 5.68 \\
\hline
\end{tabular}


occasions when tutors did not pursue prey or did not eat within a trial.

Statistical analysis. All statistical analyses were conducted using $\mathrm{R}$ version 2.9.1 (R Development Core Team 2009). The statistical methods described below are explained in Crawley (2007).

We applied a generalized linear model (glm) for proportion data to test the effect of rearing environment on prey capture success. The R-syntax for the model used was:

\section{glm(cbind(Eaten,Not.eaten) Condition.Factor+ Rearing*Tutor*Prey.type, quasibinomial)}

The model tests for effects on the response variable proportion of prey eaten as function of the predictors rearing, tutor, prey-type and any interactions between these. Condition factor is treated as a covariate to control for an eventual effect of condition of the fish. The statement 'quasibinomial' was used instead of binomial to take overdisperision into account. Overdispesion means that the data are skewed and aggregated. Thus, F-tests instead of chi-tests were used when testing predictors.

To test the clearance rate of prey, we used a survival analysis with censoring, since not all prey was eaten within the $15 \mathrm{~min}$ of observation. We also used the cluster-function, which asserts that subjects (prey) with the same value of the variable Fish.nr may be correlated. This accounts for individual variation in the feeding activity of fish and that we have inspected clearance of prey by the same fish repeated times. Condition factor is treated as a covariate to control for an eventual effect of condition of the fish. The R-syntax for the full model used was:

survreg(Surv(Time.Eaten,Status) $\sim C+$ Condition . Factor+Rearing +Tutor+Rearing:Tutor, dist='weibull')

where $C$ is the object defining clustering of prey data within individual fish. This object was created by the cluster-function through the following syntax: c <cluster(Fish.nr). The response variable (Time.Eaten) is the time (s) it took before a prey was ingested. We tested each predictor through forward selection.

Except for no clustering variable, we used the same type of model when analysing the time it took for individual fish to start feeding depending on Rearing and Tutor.

When there was an effect of the predictor called Tutor in any of the above models, we used contrast analysis to reveal which of the 3 levels of Tutor (control, gammarids and mysids) differed.

The non-parametric Wilcoxon rank-sum test was used to test if tutor rank differed between those fed gammarid and those fed mysids. Hence, this tested if one prey typically was taken quicker than the other.

\section{RESULTS}

Naïve enriched fish started feeding sooner than naïve plain fish ( $p=0.043$; Fig. $2 \mathrm{a}$; Table 2 ), and a comparison of the frequency with which fish started feeding within 5 min reveals that 16 enriched fish had begun feeding compared to only 6 plain fish (chisquare; $\mathrm{p}=0.009$ ). There was no effect of tutor type on when fish started to feed (Fig. 2b; Table 2).

Naive fish showed a clear preference for gammarids over mysids ( $p<0.001$, Tables $3 \& 4$ ). Naïve fish ate a total of 109 gammarids compared to 61 mysids (Table 4). The calculated prey rank further show that, overall, naïve fish ate gammarids earlier in trials (prey

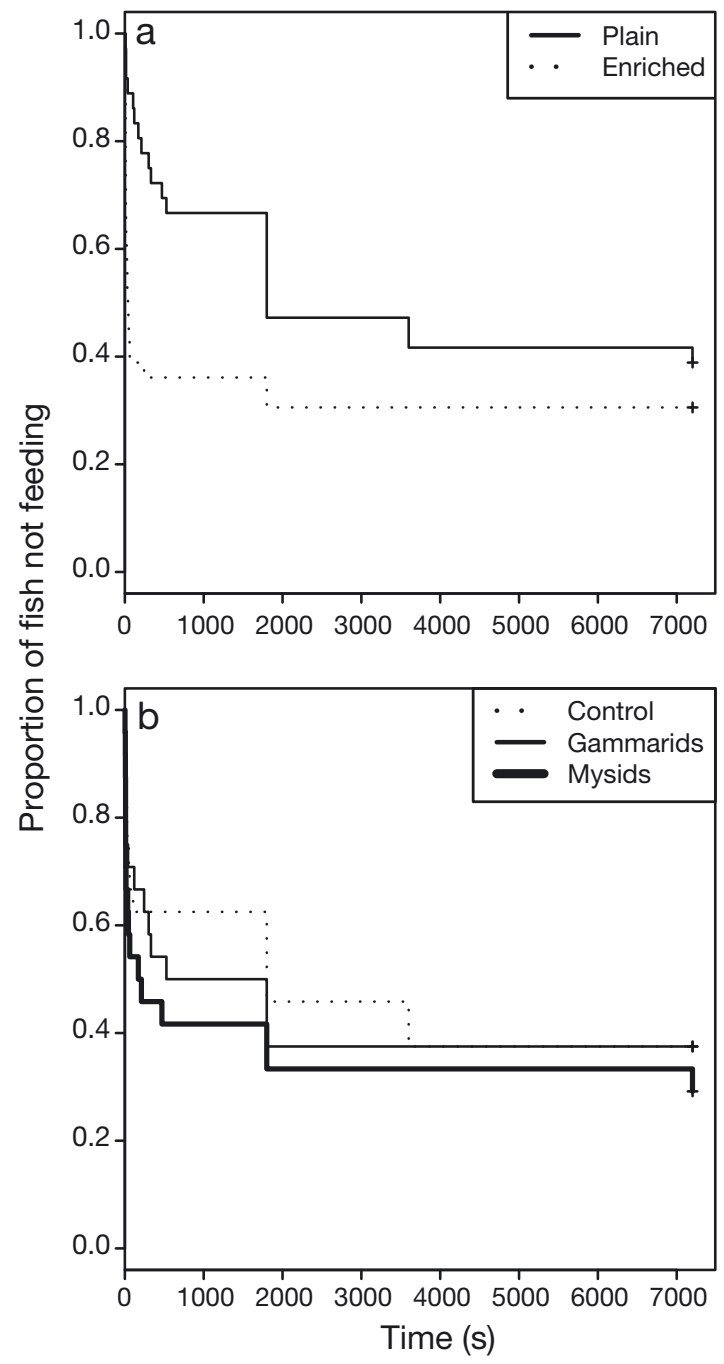

Fig. 2. Gadus morhua. Proportion of (a) enriched- and plainreared naïve fish not feeding on live gammarids and mysids offered, pooled over tutor groups; and (b) of naïve fish not feeding on such prey, for those watching tutors feeding on gammarids, mysid or not feeding (control). Data from naïve enriched- and plain-reared fish are pooled 
Table 2. Survival analysis results, testing the time it took for an individual naïve fish to start feeding, and effect of rearing environment and tutor. Effects starting from a null model and adding the given predictors. Condition factor is added first to control for an eventual effect of condition of the fish. A low $-2{ }^{*} \mathrm{LL}$ value $\left(-2{ }^{*}\right.$ log-likelihood) relative to the other models means this model explains the clearance rate better. p-values refer to the comparison using chi-test of the given model as compared to the model above in explaining the data

\begin{tabular}{|c|c|c|c|c|c|}
\hline Predictor & $-2 * \mathrm{LL}$ & Residual df & Test df & Deviance & $\mathrm{p}$-value \\
\hline $\begin{array}{l}\text { Null model: } \\
\text { survreg(Surv(Time.Eaten,Status) 1, dist='weibull') }\end{array}$ & 743.145 & 70 & & & \\
\hline + Condition.Factor & 742.286 & 69 & 1 & 0.859 & 0.354 \\
\hline + Rearing & 738.176 & 68 & 1 & 4.110 & 0.043 \\
\hline + Tutor & 736.423 & 66 & 2 & 1.753 & 0.416 \\
\hline + Rearing:Tutor & 736.262 & 64 & 2 & 0.160 & 0.923 \\
\hline
\end{tabular}

rank mean: $2.14 \pm 0.11 \mathrm{SE})$ than mysid prey $(3.88 \pm$ 0.19). While $40 \%$ of the mysids pursuits led to consumption, $53 \%$ of the attempts at capturing gammarids were successful. Also, tutors cleared gammarids (tutor rank: $1.30 \pm 0.14)$ faster than mysids $(2.15 \pm 0.14)$ (Wilcoxon rank sum test; $\mathrm{W}=3302.0, \mathrm{p}<0.001$ ). All gammarids were eaten within $5 \mathrm{~min}$, while it took 10 to $15 \mathrm{~min}$ for the tutors to consume the same number of mysids.

Both rearing environment and tutor had a significant effect on the prey capture success of naïve fish $(\mathrm{glm}$; Fig. 3; Table 3). A contrast analysis demonstrated that the tutor effect was due to a significant difference between fish watching mysid tutors compared to those watching controls $(p=0.009)$, suggesting that naïve fish that had observed tutors demonstrating eating mysid prey learned a food association faster than naïve fish observing control tutors (Figs. $3 \& 4$; Table 3 ). The contrast analysis further showed no difference between fish watching control and gammarid tutors ( $p=0.209$ ) nor those watching gammarid and mysid tutors $(\mathrm{p}=0.148)$.

Survival analysis tested the clearance rate of prey and showed that both the rearing environment and the
Table 4. Gadus morhua. Total number of prey eaten within each treatment group

\begin{tabular}{|lcc|}
\hline Predictor & Levels & Prey eaten \\
\hline Rearing & Plain & 67 \\
& Enriched & 103 \\
Tutor & Control & 45 \\
& Gammarid & 56 \\
\multirow{3}{*}{ Prey type } & Mysid & 69 \\
& Gammarid & 109 \\
& Mysid & 61 \\
\hline
\end{tabular}

tutor group had a significant effect, but there were no interactions (Table 5). A contrast analysis showed that the tutor effect was due to fish that observed mysid tutors versus those that saw controls $(p=0.001)$, and gammarid tutors versus controls ( $p=0.035)$, while the mysid and gammarid groups were not different $(\mathrm{p}=$ 0.203). This suggests that observing the tutor fish forage on live prey influences how efficiently naïve fish learn to eat prey.

Table 3. Results from a generalized linear model on probability that a prey is eaten depending on rearing environment of naïve fish pursuing the prey, tutor and prey types. Condition factor was treated as a covariate to control for an eventual effect of condition of the fish. ${ }^{*} \mathrm{p}<0.05,{ }^{* * *} \mathrm{p}<0.001$

\begin{tabular}{|lcccccc|}
\hline & df & Deviance & Residual df & Residual deviation & $F$ & $p$-value \\
\hline NULL & & & 143 & 395.29 & & \\
Condition.Factor & 1 & 5.858 & 142 & 389.43 & 2.604 & 0.109 \\
Rearing & 1 & 14.411 & 141 & 375.02 & 6.405 & $0.013^{*}$ \\
Tutor & 2 & 17.013 & 139 & 358.01 & 3.781 & $0.025^{*}$ \\
Prey.type & 1 & 31.903 & 138 & 326.11 & 14.180 & $<0.001^{* * *}$ \\
Rearing:Tutor & 2 & 1.090 & 136 & 325.02 & 0.242 & 0.785 \\
Rearing:Prey.type & 1 & 2.910 & 135 & 322.11 & 1.294 & 0.257 \\
Tutor:Prey.type & 2 & 1.221 & 133 & 320.88 & 0.271 & 0.763 \\
Rearing:Tutor:Prey.type & 2 & 1.610 & 131 & 319.27 & 0.358 & 0.700 \\
\hline
\end{tabular}




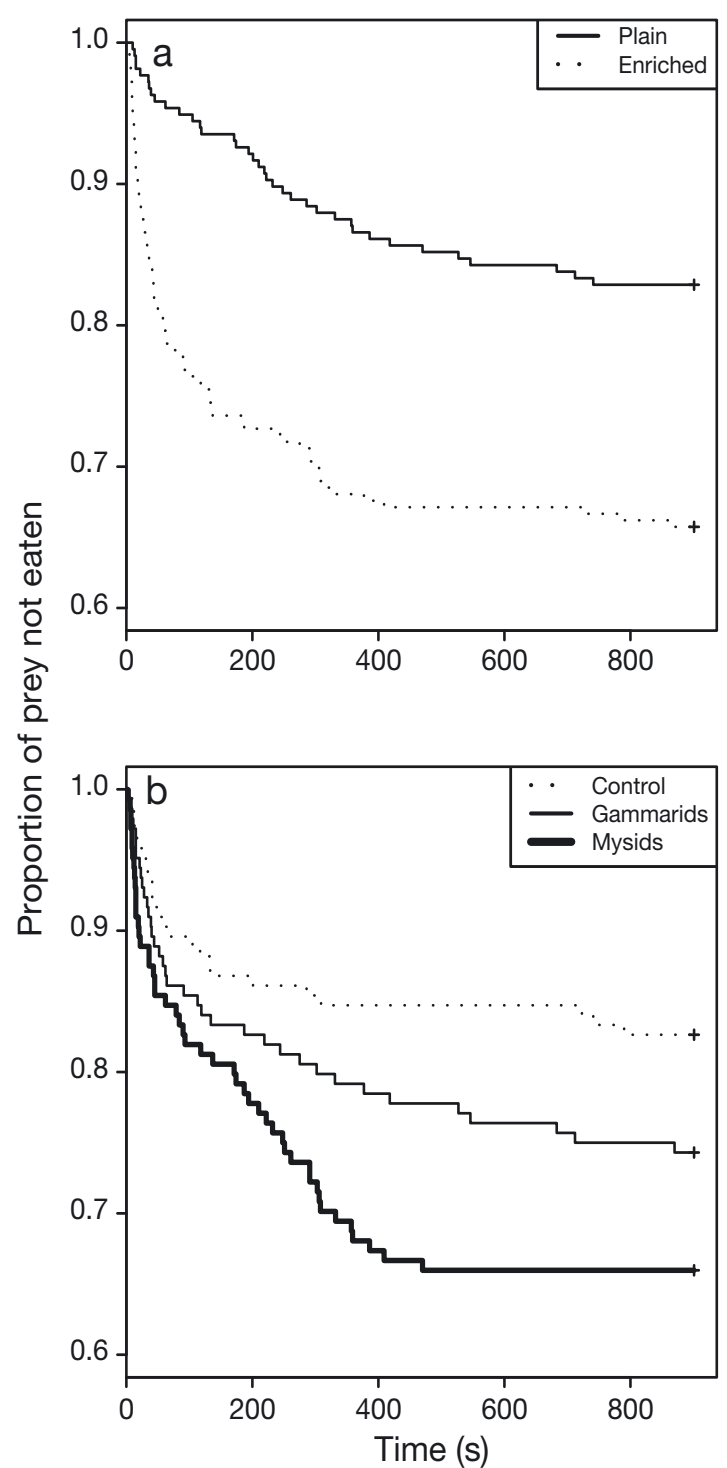

Fig. 3. Prey survival during the first $15 \mathrm{~min}$. (a) Effect of rearing environment; (b) tutor effect

\section{DISCUSSION}

Our results are consistent with earlier findings demonstrating that enrichment improves the way animals respond to new situations. The data showed that rearing background influenced learning and how fish responded to social stimuli. Enriched fish had higher food intake than plain fish for both prey types on the test day when they were not in visual contact with foraging tutor fish. There was an effect of what kind of prey their tutor fish had been eating: while more gammarids were eaten and cleared more quickly than mysids both by tutor and naïve fish, naïve fish watching mysid-foraging tutors learned a food association

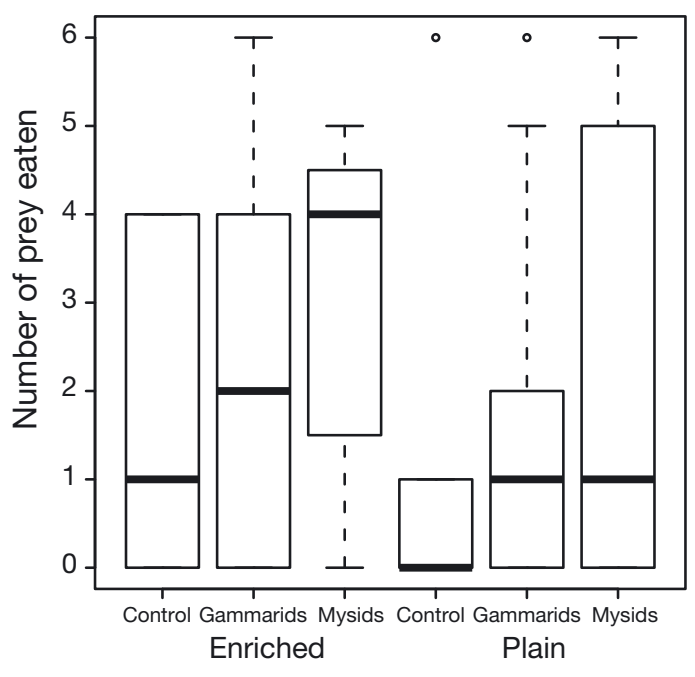

Fig. 4. Gadus morhua. Prey eaten within the first $30 \mathrm{~min}$ by enriched- and plain-reared naïve fish of different tutor groups (watching tutors feeding on gammarids, mysids or not feeding [control] on Day 1). Values portrayed are the standard boxand-whisker plot in R, i.e. median, 1st and 3rd quartile (Q1 and Q3). Whiskers represent max. and min. values except for outliers (defined as 1.5 times the length of the box away from the box)

faster. This suggests that exposure to foraging demonstrators has a positive effect on food intake. The finding that enrichment in the early rearing environment promotes learning abilities in fish supports and adds to our previous findings that environmental complexity in the rearing environment enhances fish behavioural repertoire (Braithwaite \& Salvanes 2005, Salvanes \& Braithwaite 2005, Salvanes et al. 2007). It is not new that fish can learn and remember how to handle different prey, nor that what is learned varies across populations (Mackney \& Hughes 1995), but rather, here we find a novel effect of spatial enrichment on learning. These behavioural skills are likely to be important for growth and survival in nature.

Although transferring the naïve fish into the test compartments represents a significant change for the fish, all naïve fish were allowed a long acclimation period of $43 \mathrm{~h}$ to help them settle within the test aquaria. During much of the second day during the acclimation period, the naïve fish were able to see tutor fish and thus had social stimuli in their environment during the times the tutor fish demonstrated how to feed on live prey. The tutor fish almost always began feeding as soon as prey were available, and all tutors fed in the test aquaria, indicating that the small test aquaria did not overtly decrease motivation to feed. Further, the results from naïve test fish demonstrate a clear difference between plain and enriched fish, and other differences between them have been found in 
Table 5. Survival analysis results, testing clearance rate of prey depending on rearing environment of naïve fish and tutor. See Table 2 for further description

\begin{tabular}{|c|c|c|c|c|c|}
\hline Model & $-2 * \mathrm{LL}$ & Residual df & Test df & Deviance & p-value \\
\hline $\begin{array}{l}\text { Null model: } \\
\text { survreg(Surv(Time.Eaten,Status) } \sim \text {, dist='weibull') }\end{array}$ & 1844.384 & 429 & & & \\
\hline + Condition.Factor & 1844.045 & 428 & 1 & 0.339 & 0.560 \\
\hline + Rearing & 1825.595 & 427 & 1 & 18.450 & $<0.001$ \\
\hline + Tutor & 1813.187 & 425 & 2 & 12.408 & 0.002 \\
\hline + Rearing:Tutor & 1812.600 & 423 & 2 & 0.587 & 0.746 \\
\hline
\end{tabular}

previous studies using similar test conditions (e.g. Artigas et al. 2005, Braithwaite \& Salvanes 2005).

The effect of spatially enriched rearing environments on rodent behaviour is well documented, and spatial enrichment has been shown to affect both behavioural flexibility, neuroanatomy and stress responses. Recently, it was shown that the cognitive benefits of enrichment in rats arose because of better stress coping abilities during cognitive testing (Harris et al. 2009). If housed in enriched cages, rats and mice show increased exploratory behaviour and have an enlarged hippocampus: a region of the brain linked to learning and memory processes (Chapillon et al. 1999, Nilsson et al. 1999, Sackett et al. 1999, Zimmermann et al. 2001). Furthermore, interactions with conspecifics during the early phases of life can have an impact on the development of social behaviours in rodents (Laviola \& Terranova 1998). Although these kinds of effects were not explored in this study, our results suggest experiences with enrichment in fish generate similar behavioural changes to those quantified for rodents.

Exposure to social cues in the early rearing environment influence later social learning abilities in guppies Poecilia reticulata. Individuals reared in low-density groups were better at using social information and locating food than guppies reared at higher densities (Chapman et al. 2008). These results suggest that group size affects learning. The probability of learning from demonstrators tends to decline with increasing numbers of observers possibly because naïve animals observe non-informed individuals rather than informed demonstrators in larger groups (Croney \& Newberry 2007). In our experiments, group sizes were the same for the enriched and plain groups during rearing. Thus, our results show that the physical and visual environment also influence learning in a social context since enriched fished learned a food association faster. Enriched fish cleared prey faster and took more prey on Day 2 even in the absence of tutors. To our knowledge, our data are the first to show that physical enrichment influenced social learning in fish, a behavioural trait that will save the cost of learning by more costly trial-and-error learning (Laland 2004).
We have shown that juvenile cod are capable of learning to capture and feed on novel prey, and that the spatial environment in which the cod were raised influences their ability to learn and how they respond to visual cues from feeding conspecifics. The data showing the effect of watching mysids suggests that the behaviour of the prey may have indirect effects on how quick a food association is learned. It is, however, not possible from our data to disentangle if this was due to an effect of time spent foraging of the mysid tutors (which was longer compared to the gammarid and the control tutors), from a potential indirect effect of prey behaviour. Both enriched and plain naïve cod were better at catching gammarids. The most likely explanation is that mysids are more transparent and might be harder to detect than gammarids, and have an evasive anti-predator response that triggers tail flip escape swimming when attacked by predators (Neil \& Ansell 1995). Gammarids, on the other hand, lack this response and typically move more, which increases the potential contact rate between fish and prey and thus increase the predation rate on gammarids.

Considerable social information can be transmitted inadvertently as demonstrators sample the environment, and one could argue that this does not require them to have more knowledge than the observer. Social learning works by animals obtaining information from more knowledgeable or more skilled individuals. Learning from others saves an individual the cost of trial and error learning, but it requires individuals to have some capacity to discriminate the pay-offs associated with social versus trial-and-error learning (Laland 2004). For example, guppies are able to discriminate between informed and non-informed individuals and choose to follow informed individuals (Lachlan et al. 1998). The mechanism underpinning the social learning differences we observed in the enriched cod is unclear. It may be that having objects within the rearing environment alters the feeding behaviour of the fish and somehow encourages individuals to watch conspecifics. However, the current results and a previous study, where enriched cod were found to be more selective in terms of which individuals they were 
aggressive towards (Salvanes \& Braithwaite 2005), suggest that enrichment improves general social behaviour. Further experiments are now required to determine the underlying causes of these improved social behaviours. Understanding how both the social and physical environment affects learning ability is important in relation to fish reared for supplementing natural populations, but this knowledge will also be relevant for conservation and management of the marine environment.

Acknowledgements. This work was funded by the University of Bergen Meltzer fund. We very much appreciate the comments from A. Fernø. We thank Saga Fjord Sea Farm A/S for providing the fish, and F. Midtøy, M. Hordnes and O. Moberg for technical assistance.

\section{LITERATURE CITED}

Artigas ML, Skjæraasen JE, Utne-Palm AC, Nilsen T (2005) Recovery from handling stress in Gadus morhua. J Fish Biol 67:384-391

Berejikian BA, Tezak EP, Flagg TA, LaRae AL, Kummerow E, Mahnken CVW (2000) Social dominance, growth, and habitat use of age-0 steelhead (Oncorhynchus mykiss) grown in enriched and conventional hatchery rearing environments. Can J Fish Aquat Sci 57:628-636

Berejikian BA, Tezak EP, Riley SC, LaRae AL (2001) Competitive ability and social behaviour of juvenile steelhead reared in enriched and conventional hatchery tanks and a stream environment. J Fish Biol 59:1600-1613

Braithwaite VA (2006) Cognitive ability in fish. In: Sloman KA, Wilson RW, Balshine S (eds) Fish physiology, Vol 24. Behaviour and physiology of fish. Academic Press, San Diego, CA, p 1-37

Braithwaite VA, Salvanes AGV (2005) Environmental variability in the early rearing environment generates behaviourally flexible cod: implications for rehabilitating wild populations. Proc R Soc Lond B Biol Sci 272:1107-1113

Braithwaite VA, Salvanes AGV (2008) Cognition: learning and memory. In: Magnhagen C, Braithwaite VA, Forsgren E, Kapoor BG (eds) Fish Behaviour. Science Publisher, Enfield, NH

Bredy TW, Humpartzoomian RA, Cain DP, Meaney MJ (2003) Partial reversal of the effect of maternal care on cognitive function through environmental enrichment. Neuroscience 118:571-576

Brown C, Laland K (2001) Social learning and life skills training for hatchery reared fish. J Fish Biol 59:471-493

Brown C, Laland K (2002) Social enhancement and social inhibition of foraging behaviour in hatchery-reared Atlantic salmon. J Fish Biol 61:987-998

Brown C, Laland KN (2003) Social learning in fishes: a review. Fish Fish 4:280-288

Brown C, Davidson T, Laland K (2003) Environmental enrichment and prior experience of live prey improve foraging behaviour in hatchery-reared Atlantic salmon. J Fish Biol 63:187-196

Chapillon P, Manneche C, Belzung C, Caston J (1999) Rearing environmental enrichment in two inbred strains of mice: 1. Effects on emotional reactivity. Behav Genet 29: 41-46

Chapman BB, Ward AJW, Krause J (2008) Schooling and learning: early social environment predicts social learning ability in the guppy, Poecilia reticulata. Anim Behav 76:923-929

Clayton NS, Krebs JR (1994) Hippocampal growth and attrition in birds affected by experience. Proc Natl Acad Sci USA 91:7410-7414

Crawley MJ (2007) The R book. R: a language and environment for statistical computing. R Foundation for Statistical Computing, Vienna

Croney CC, Newberry RC (2007) Group size and cognitive processes. Appl Anim Behav Sci 103:215-228

> Harris AP, D'Eath RB, Healy SD (2009) Environmental enrichment enhances spatial cognition in rats by reducing thigmotaxis (wall hugging) during testing. Anim Behav 77:1459-1464

- Hunter SA, Bay MS, Martin ML, Hatfield JS (2002) Behavioral effects of environmental enrichment on harbor seals (Phoca vitulina concolor) and gray seals (Halichoerus grypus). Zoo Biol 21:375-387

> Kempermann G, Gast D, Gage FH (2002) Neuroplasticity in old age: sustained five fold induction of hippocampal neurogenesis by long-term environmental enrichment. Ann Neurol 52:135-143

Lachlan RF, Crooks L, Laland KN (1998) Who follows whom? Shoaling preferences and social learning of foraging information in guppies. Anim Behav 56:181-190

Laland KN (2004) Social learning strategies. Learn Behav 32:4-14

Laland KN, Janik VM (2006) The animal cultures debate. Trends Ecol Evol 21:542-547

> Laland KN, Williams K (1997) Shoaling generates social learning of foraging information in guppies. Anim Behav 53:1161-1169

> Laviola G, Terranova ML (1998) The developmental psychobiology of behavioural plasticity in mice: the role of social experiences in the family unit. Neurosci Biobehav Rev 23:197-213

Leadbeater E, Chittka L (2007) Social learning in insects from miniature brains to consensus building. Curr Biol 17: R703-R713

> Mackney PA, Hughes RN (1995) Foraging behaviour and memory window in sticklebacks. Behaviour 132: 1241-1253

Magurran AE (2005) Evolutionary ecology: the Trinidadian guppy. Oxford University Press, Oxford

> Meehan CL, Mench JA (2002) Environmental enrichment affects the fear and exploratory responses to novelty of young Amazon parrots. Appl Anim Behav Sci 79:75-88

Morgan MJ, Colgan PW (1987) The effects of predator presence and shoal size on foraging in bluntnose minnows, Pimephales notatus. Environ Biol Fishes 20:105-111

Morgan MJ, Colgan PW (1988) The role of experience in foraging shoals of bluntnose minnows (Pimephales notatus). Behav Processes 16:87-93

> Neil DM, Ansell AD (1995) The orientation of tail-flip escape swimming in decapod and mysid crustaceans. J Mar Bio Assoc UK 75:55-70

Nilsson M, Perfilieva E, Johansson U, Orwar O, Eriksson PS (1999) Enriched environment increases neurogenesis in the adult rat dentate gyrus and improves spatial memory. J Neurobiol 39:569-578

> Pitcher TJ, House AC (1987) Foraging rules for group feeders: area copying depends upon food density in shoaling goldfish. Ethology 76:161-167

Pitcher TJ, Magurran AE, Winfield IJ (1982) Fish in larger shoals find food faster. Behav Ecol Sociobiol 10:149-151

Rabin LA (2003) Maintaining behavioural diversity in captiv- 
ity for conservation: natural behaviour management. Anim Welf 12:85-94

Reader SM, Kendal JR, Laland KN (2003) Social learning of foraging sites and escape routes in wild Trinidadian guppies. Anim Behav 66:729-739

Ryer CH, Olla BL (1991) Information transfer and the facilitation and inhibition of feeding in a schooling fish. Environ Biol Fishes 30:317-323

Ryer CH, Olla BL (1992) Social mechanisms facilitating exploitation of spatially variable ephemeral food patches in a pelagic marine fish. Anim Behav 44:69-74

Sackett GP, Novak M, Kroeker R (1999) Early experience effects on adaptive behavior: theory revisited. Ment Retard Dev Disabil Res Rev 5:30-40

Editorial responsibility: Roger Hughes,

Bangor, UK
Salvanes AGV, Braithwaite VA (2005) Exposure to variable spatial information in the early rearing environment generates asymmetries in social interactions in cod (Gadus morhua). Behav Ecol Sociobiol 59:250-257

Salvanes AGV, Moberg O, Braithwaite VA (2007) Effects of early experience on group behaviour in fish. Anim Behav 74:805-811

Suboski MD (1989) The acquisition of stimulus-control over released pecking by hatchling chicks (Gallus-Gallus). Can J Psychol 43:431-443

Zimmermann A, Stauffacher M, Langhans W, Wurbel H (2001) Enrichment-dependent differences in novelty exploration in rats can be explained by habituation. Behav Brain Res 121:11-20

Submitted: March 9, 2010; Accepted: June 1, 2010

Proofs received from author(s): July 27, 2010 